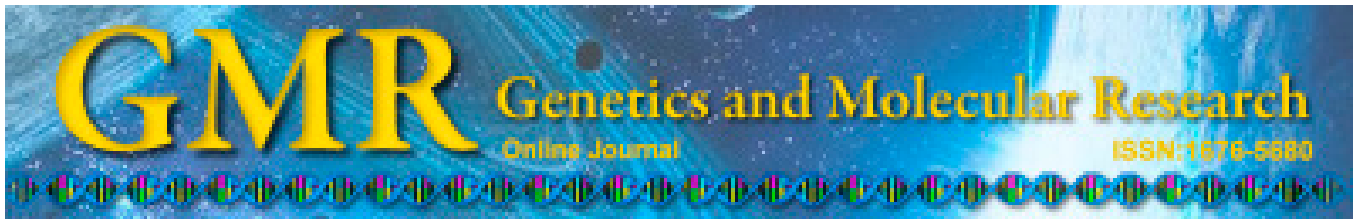

\title{
Relationship between polymorphisms in exon 10 of FSHR gene and litter size in swine
}

\author{
X.D. Zhang ${ }^{1,2 *}$, H.Y. Zhu ${ }^{1,2 *}$, J. Zhou ${ }^{1}$, N. Wang ${ }^{1}$, N. Zhou ${ }^{1}$, L. Huang ${ }^{1,2}$, \\ T. Wu ${ }^{1,2}$, Y.F. Feng ${ }^{1,2}$, Y.Y. Ding ${ }^{1,2}$ and Z.J. Yin ${ }^{1,2}$ \\ ${ }^{1}$ College of Animal Science and Technology, Anhui Agricultural University, \\ Hefei, China \\ ${ }^{2}$ Anhui Provincial Laboratory of Local Animal Genetic Resources \\ Conservation and Bio-Breeding, Hefei, China \\ *These authors contributed equally to this study. \\ Corresponding author: J. Zhou \\ E-mail: xdzhang1983@163.com
}

Genet. Mol. Res. 14 (3): 8252-8261 (2015)

Received September 29, 2014

Accepted April 24, 2015

Published July 27, 2015

DOI http://dx.doi.org/10.4238/2015.July.27.13

\begin{abstract}
Follicle-stimulating hormone (FSH), a glycoprotein secreted by the anterior pituitary, can regulate ovarian function through the FSH receptor $(F S H R)$. To evaluate the effects of the FSHR gene on reproductive traits in pigs, polymorphisms in exon 10 of the FSHR gene were observed by polymerase chain reaction-single-strand conformation polymorphism, and 3 single nucleotide polymorphisms (C1491T, G1885A, and C1977T) in exon 10 of the porcine FSHR gene, and 3 genotypes (AA, AB, and BB) for C1491T and 2 haplotypes (D and E) for G1885A and C1977T were identified. Further analysis of single nucleotide polymorphism genotypes associated with reproductive traits including total number born (TNB) and number born alive (NBA) was carried out in 3 pig populations including Berkshire, Wannan Black (a Chinese indigenous pig breed), and BW pigs (two-way crossbred pigs produced from Berkshire $\delta$ and Wannan Black pig +). The results showed that the TNB and NBA of Wannan Black pigs with the AB genotype were significantly higher than in AA genotype sows $(\mathrm{P}<0.01)$
\end{abstract}


in multiparity sows and all parities. The TNB and NBA of Berkshire pigs with the DE genotype were significantly higher than the DD and EE genotype sows $(P<0.01)$ in gilts, sows and all parities. Overall, TNB and NBA from the 3 identified genotypes was DE $>$ DD $>$ EE. The results showed that polymorphisms in exon 10 of the FSHR gene had a significant effect on litter size traits of Wannan Black and Berkshire pigs. These results can be applied for marker-assisted selection in the 2 swine breeds.

Key words: Follicle-stimulating hormone receptor; Polymorphism; Number born alive; Pig; Total number born

\section{INTRODUCTION}

Porcine reproductive traits directly affect production and the economic efficiency of pig farms. Reproductive processes are mainly regulated by the endocrine system. Folliclestimulating hormone (FSH), a glycoprotein secreted by the anterior pituitary, can regulate ovarian function through the FSH receptor (FSHR) (Rannikki et al., 1995). cDNA open reading frames of human and most mammalian FSHR genes contain 10 exons and 9 introns, with exon 10 encoding transmembrane and intracellular domains (Marsters et al., 2003; Daelemans et al., 2004). Sequence analysis of exon 10 of FSHR has mainly focused on human samples (Achrekar et al., 2009a; Balkan et al., 2010; Rendina et al., 2010; Dolfin et al., 2011; Grigorova et al., 2008, 2013). More than 700 single nucleotide polymorphisms (SNPs) have been identified in the human FSHR gene and are known to impact fertility (Sudo et al., 2002; Daelemans et al., 2004; Jun et al., 2006; Vilodre et al., 2008; Achrekar et al., 2009b; Rodini et al., 2011; Mohiyiddeen et al., 2012). Based on these findings, it has been suggested that polymorphisms in the FSHR gene of livestock may also play a role in fertility. While few studies have examined FSHR gene polymorphisms in livestock, most polymorphisms identified have been found in the 5'-region of the gene (Chu et al., 2012; Zhang et al., 2004, 2012; Yang et al., 2014). Kang et al. (2012) indicated that chicken FSHR gene polymorphisms influence the age at first egg. A study by Rahal et al. (2000) detected 2 SNPs (C1506T and T1593C) in exon 10 of the bovine FSHR gene. Marson et al. (2008) found no correlation between FSHR gene polymorphisms and precocious puberty in heifers, while a study by Sairam and Subbarayan (1997) identified a correlation between FSHR gene polymorphisms and the secretion of reproductive hormones in seasonally breeding mammals. Finally, studies by Jiang et al. (2002) revealed that polymorphisms in exon 10 of the porcine FSHR gene significantly affected the number of offspring. More extensive studies examining the effects of polymorphisms in the porcine FSHR gene have not been reported.

Wannan Black pigs, a Chinese native breed from Anhui Province, display high fertility. The Berkshire pig is a lean pig breed from American. In this study, we used polymerase chain reaction-single-strand conformation polymorphism (PCR-SSCP) methods to examine polymorphisms in exon 10 of the FSHR gene in Wannan Black pigs, BW pigs (2-way crossbred pigs produced from Berkshire $\hat{\sigma}$ and Wannan Black pig ()), and Berkshire pigs. We studied the relationship between polymorphisms and the number of offspring in order to provide a reference for the breeding of local pig breeds as well as for the conservation and utilization of germplasm resources. 


\section{MATERIAL AND METHODS}

\section{Sample sources and data collection}

Ear tissue samples were collected from 3 varieties of sows from a total of 253 samples, of which 91 were obtained from Wannan Black pigs, 82 from BW pigs, and 80 from Berkshire pigs. Information collected on the 253 sows included birth parity, total number born (TNB), and number born alive (NBA). Ear tissue samples were placed in centrifuge tubes in $70 \%$ ethanol and cryopreserved at $-20^{\circ} \mathrm{C}$. Phenol-chloroform extraction was used to obtain DNA from ear tissues. The DNA was resuspended in Tris-EDTA buffer and UV spectrophotometry was used to determine the concentration and quality of DNA. The DNA was then diluted to 50 $\mathrm{ng} / \mu \mathrm{L}$ and cryopreserved at $-20^{\circ} \mathrm{C}$.

Nutrition and management conditions for pigs were consistent between the 3 groups. Hybridization, production, and epidemic prevention of the groups were conducted in strict accordance with the production standards of the pig-breeding farm. Experiments were performed according to the Regulations for the Administration of Affairs Concerning Experimental Animals (Ministry of Science and Technology, China; revised June 2004) and approved by the Ethics Committee of Anhui Agricultural University, Anhui, China, under permission No. AHAU20140215.

\section{PCR-SSCP}

PCR was performed in a volume of $25 \mu \mathrm{L}$ and included $8 \mu \mathrm{L} 2 \mathrm{X}$ Power Taq PCR MasterMix, $2 \mu \mathrm{L}$ template DNA, $1 \mu \mathrm{L}$ of each $2 \mu \mathrm{M}$ upstream and downstream primers, and $13 \mu \mathrm{L}$ sterile distilled water. The PCR amplification program included an initial denaturation step at $94^{\circ} \mathrm{C}$ for $5 \mathrm{~min}$, denaturation at $94^{\circ} \mathrm{C}$ for $1 \mathrm{~min}$, annealing at $55.5^{\circ}-60.4^{\circ} \mathrm{C}$ for $30 \mathrm{~s}$, and extension at $72^{\circ} \mathrm{C}$ for $30 \mathrm{~s}$ for a total of 31 cycles, followed by extension at $72^{\circ} \mathrm{C}$ for 10 min and holding at $4^{\circ} \mathrm{C}$. Primers were designed according to the literature (Wu and Wang, 2012) and were synthesized by Shanghai Biological Engineering Technology Services Co., Ltd. (Shanghai, China). Primer sequences are shown in Table 1.

\begin{tabular}{|c|c|c|c|c|}
\hline Primer & Sequences & Position in NM_214386 (bp) & Annealing temperature $\left({ }^{\circ} \mathrm{C}\right)$ & Product length (bp) \\
\hline \multirow[t]{2}{*}{$\overline{\text { FP1 }}$} & F: 5'-atgtgatttgctcccctgag-3' & 1064 & 55.8 & 174 \\
\hline & R: 5'-taaggaaccgagggactgtg-3' & 1237 & & \\
\hline \multirow[t]{2}{*}{ FP2 } & F: 5'-catggggcatgatattctcag-3' & 1113 & 56.9 & 243 \\
\hline & R: 5'-gctccagtttgccagtcaat-3' & 1355 & & \\
\hline \multirow[t]{2}{*}{ FP3 } & F: $5^{\prime}$-caataccacaactatgccattga-3' & 1318 & 55.5 & 243 \\
\hline & R: 5'-gatgccaaagatgggaaaga-3' & 1560 & & \\
\hline \multirow{2}{*}{ FP4 } & F: $5^{\prime}$-tctttcccatctttggcatc-3' & 1541 & 56.9 & 243 \\
\hline & R: 5'-ggaagtccgtgaagatgagc-3' & 1783 & & \\
\hline \multirow[t]{2}{*}{ FP5 } & F: 5'-tatggecatgctcattttca-3' & 1755 & 60.4 & 248 \\
\hline & R: 5'-tcctataagtctgggcttgcat-3' & 2002 & & \\
\hline \multirow[t]{2}{*}{ FP6 } & F: 5'-gctaagcaagtttggctgct-3' & 1956 & 56.9 & 164 \\
\hline & R: 5'-tctgggctaaacggcttaaa-3' & 2119 & & \\
\hline
\end{tabular}

$\mathrm{F}$ is the upstream primer; $\mathrm{R}$ is the downstream primer. 
SSCP analysis was performed using $2.5 \mu \mathrm{L}$ PCR product in $7.5 \mu \mathrm{L}$ loading buffer ( 9 $\mathrm{mL}$ deionized formamide, $1 \mathrm{~mL} 10 \mathrm{X}$ Tris-borate-EDTA buffer, $0.025 \%$ bromophenol blue, and $0.025 \%$ xylene cyanide). Samples were mixed and denatured at $98^{\circ} \mathrm{C}$ for $10 \mathrm{~min}$, then placed in an ice bath for $10 \mathrm{~min}$. Samples were then run on a $10 \%$ polyacrylamide gel pre-run at $300 \mathrm{~V}$ for $20 \mathrm{~min}$, followed by electrophoresis at $120 \mathrm{~V}$ for $12 \mathrm{~h}$. The gel was silver-stained and images were obtained. Sequencing was performed by the Beijing Genomics Institute (Beijing, China).

\section{Statistical analysis}

The SPSS17.0 statistical analysis software (SPSS, Inc., Chicago, IL, USA) was used to calculate gene (haplotype) and genotype frequencies, as well as to perform a significance test of the difference between gene (haplotype) and genotype frequency ( $\chi^{2}$ independence test), gene heterozygosity, and the effective number of alleles (Weaver and Wuensch, 2013). The SHEsis analysis software was used to calculate the parameters of linkage disequilibrium (Shi and He, 2005). In this test, the general linear model procedure of the SPSS17.0 statistical analysis software was used for correlation analysis between FSHR gene polymorphisms and TNB and NBA. The least significant difference method was used for multiple comparisons, and the corresponding TNB and NBA of different genotypes are reported as the least squares means \pm standard error. The linear model was as follows:

$$
\mathrm{Y}_{\mathrm{ijk} l}=\mu+\mathrm{a}_{\mathrm{i}}+\mathrm{b}_{\mathrm{j}}+\mathrm{c}_{\mathrm{k}}+\mathrm{d}_{1}+\mathrm{e}_{\mathrm{ijkl}}
$$

where $Y_{i j k l}$ is the observed value of traits; $\mu$ is the overall mean; $a_{i}$ is the year and seasonal effect; $b_{j}$ is the genotype effect; $c_{k}$ is the effect of birth parity; $d_{l}$ is the breed effect; and $e_{i j k l}$ are random-residual effects.

\section{RESULTS}

\section{Genotyping and sequencing results}

Polymorphic loci were only detected by 2 pairs of primers (FP3 and FP5) within all 6 pairs of primers. Three genotypes $\mathrm{AA}, \mathrm{AB}$, and $\mathrm{BB}$ with primer $\mathrm{FP} 3$ and 5 genotypes $(\mathrm{CC}, \mathrm{DC}$, $\mathrm{DD}, \mathrm{DE}$, and EE) with primer FP5 were identified. Sequencing results indicated that a $\mathrm{T} \rightarrow \mathrm{C}$ mutation at the 1491-bp locus of exon 10, a $\mathrm{G} \rightarrow$ A mutation at the 1885-bp locus, and a $\mathrm{C} \rightarrow \mathrm{T}$ mutation at the 1977-bp locus (Figure 1).

\section{Linkage disequilibrium analysis and haplotype construction}

Two polymorphic loci identified using primer FP5 in Berkshire pigs were analyzed for linkage disequilibrium and haplotype construction. The results showed that 2 polymorphic loci were in strong linkage disequilibrium $(\mathrm{P}<0.01)$; theoretically, 2 polymorphic loci should have 4 haplotypes, including GT, GC, AT, and AC, but only 2 haplotypes showing statistical 
significance were identified; GC (haplotype D) and TA (haplotype E). No polymorphisms were detected using primer FP5 in Wannan Black pigs and BW pigs. GT was designated as haplotype $\mathrm{C}$ type.

A

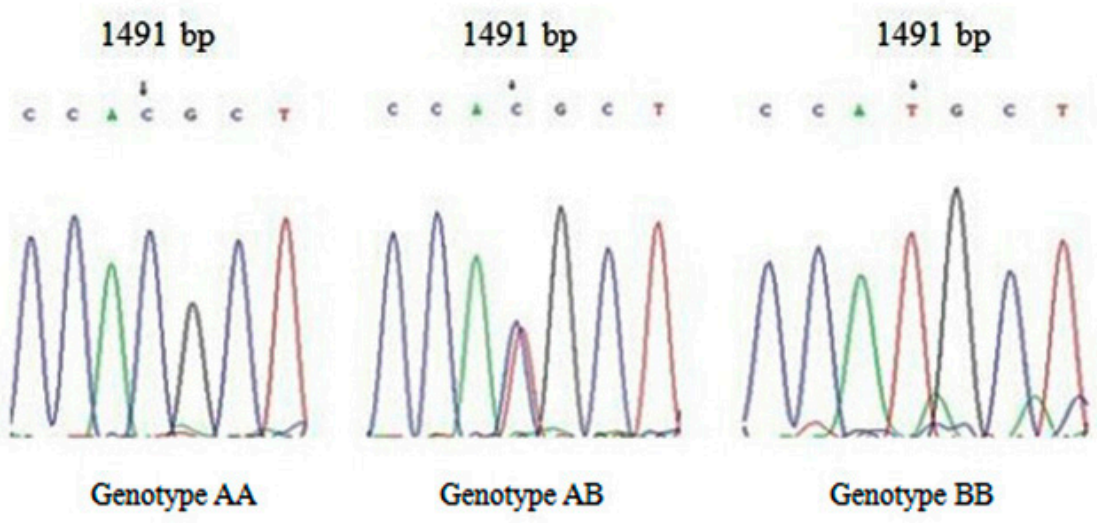

B

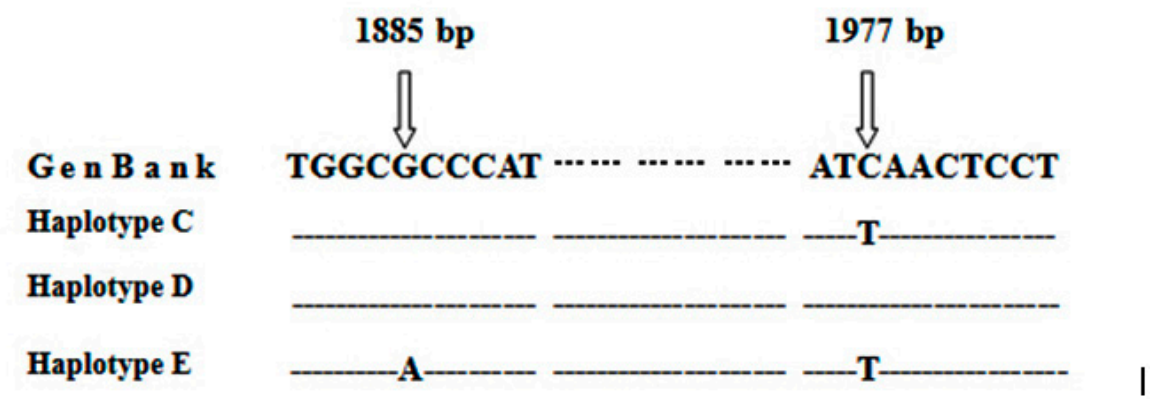

Figure 1. A. Sequence comparison of genotypes AA, AB, and BB based on sequencing using primer FP3. B. Sequence comparison of 3 haplotypes identified based on sequencing using primer FP5.

\section{Genetic polymorphism of the FSHR gene in different breeds of pigs}

Gene frequency (haplotype frequency), genotype frequency, significant difference test between gene frequency (haplotype) and genotype frequency ( $\chi^{2}$ independence test), polymorphic information content, gene heterozygosity, and effective number of alleles at the FP3 and FP5 loci in 3 pig breeds were calculated after polymorphism genotyping using PCR-SSCP analysis (Table 2). Based on statistical analysis, the most advantageous allele at the FP3 locus in Wannan Black pigs was A, and the frequency of allele A was 0.9231. The most advantageous allele at locus FP3 of BW pigs was B, and the frequency of gene B was 0.5732 . The relative haplotype frequency at the FP5 locus of Berkshire pigs was D $>\mathrm{E}$, and the frequency of haplotype D was 0.9000 . Based on the $\chi^{2}$ test, the genotype frequency at the FP3 locus in 
Wannan Black pigs was in Hardy-Weinberg equilibrium $\left(\chi^{2}=0.6319, \mathrm{P}=0.729\right)$. The genotype frequency at the FP5 locus in Berkshire pigs was also in Hardy-Weinberg equilibrium $\left(\chi^{2}\right.$ $=0.0934, \mathrm{P}=0.999)$, showing that the genotype frequencies at the FP3 locus in Wannan Black pigs and the FP5 locus in Berkshire pigs were affected by selection, mutation, migration, or other factors.

\begin{tabular}{|c|c|c|c|c|c|}
\hline Position & & & Wannan Black & BW pigs & Berkshire \\
\hline \multirow[t]{7}{*}{ FP3 } & \multirow[t]{2}{*}{ Gene frequency } & A & 0.9231 & 0.4268 & 0.0000 \\
\hline & & B & 0.0769 & 0.5732 & 1.0000 \\
\hline & \multirow[t]{3}{*}{ Genotype frequency $(\mathrm{N})$} & AA & $0.8462(77)$ & $0(0)$ & $0(0)$ \\
\hline & & $\mathrm{AB}$ & $0.1538(14)$ & $0.8537(70)$ & $0(0)$ \\
\hline & & BB & $0(0)$ & $0.1463(12)$ & $1(80)$ \\
\hline & $\chi^{2}$ value & & 0.6319 & 45.4731 & 0.0000 \\
\hline & $\mathrm{P}$ value & & 0.7290 & $<0.0010$ & 1.0000 \\
\hline \multirow[t]{10}{*}{ FP5 } & \multirow{3}{*}{ Haplotype frequency } & $\mathrm{C}$ & 1.0000 & 0.5000 & 0.0000 \\
\hline & & $\mathrm{D}$ & 0.0000 & 0.5000 & 0.9000 \\
\hline & & E & 0.0000 & 0.0000 & 0.1000 \\
\hline & \multirow{5}{*}{ Genotype frequency } & $\mathrm{CC}$ & $1(91)$ & $0(0)$ & $0(0)$ \\
\hline & & $\mathrm{DC}$ & $0(0)$ & $1(82)$ & $0(0)$ \\
\hline & & $\mathrm{DD}$ & $0(0)$ & $0(0)$ & $0.825(66)$ \\
\hline & & $\mathrm{DE}$ & $0(0)$ & $0(0)$ & $0.15(12)$ \\
\hline & & $\mathrm{EE}$ & $0(0)$ & $0(0)$ & $0.025(2)$ \\
\hline & $\chi^{2}$ value & & 0.0000 & 0.0000 & 0.0934 \\
\hline & P value & & 1.0000 & 1.0000 & 0.9990 \\
\hline
\end{tabular}

Relationship between FSHR gene polymorphisms and litter size in different breeds of pigs

The relationship between polymorphisms at the FP3 and FP5 loci and the number born of the 3 varieties of pigs was analyzed (Table 3). At the FP3 locus, in Wannan Black gilts, the TNB from pigs with the AB genotype was 1.11-fold greater than in pigs with the AA genotype $(\mathrm{P}<0.05)$. The NBA in pigs of the $\mathrm{AB}$ genotype was 0.84 -fold greater than in the AA genotype $(\mathrm{P}>0.05)$. In Wannan Black pigs, the TNB and NBA from genotype AB pigs in multiparity and all parities were significantly higher in pigs with the AA genotype $(\mathrm{P}<0.01)$.

At the FP3 locus, in primiparity, multiparity, and all parities from BW pigs, there was no significant difference in TNB and NBA between genotypes $\mathrm{AB}$ and $\mathrm{AA}(\mathrm{P}>0.05)$.

At the FP5 locus, in primiparity and all parities from Berkshire pigs, TNB and NBA from $\mathrm{DE}$ and $\mathrm{DD}$ genotypes were significantly higher than EE genotype $(\mathrm{P}<0.01)$. The overall trend of TNB and NBA for all 3 genotypes at the FP5 locus was DE $>$ DD $>$ EE.

\section{DISCUSSION}

\section{Genetic polymorphisms of FSHR}

Numerous studies have examined polymorphisms in exon 10 in the human FSHR gene, including C1043G (Pro348Arg), G1255A (Ala419Thr), A1556C (Pro519Thr), C1717T (Arg573Cys), C1723T (Ala575Val), A919G (Thr307Ala), and A2039G (Asn680Ser) (Livshyts et al., 2009; Achrekar et al., 2010). Previous studies regarding FSHR polymorphisms in animals have mainly focused on the 5'-untranslated region and exon 1. 


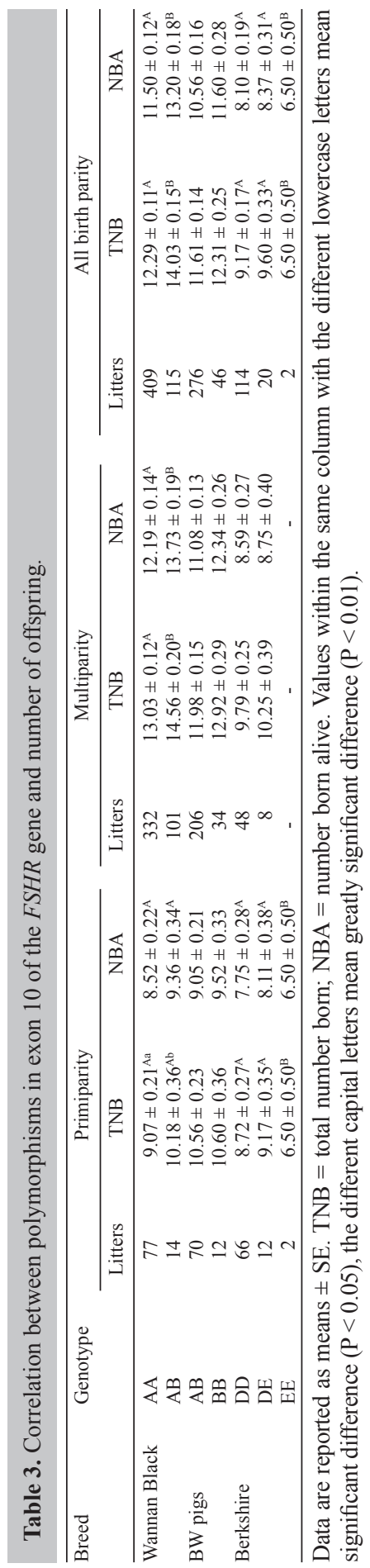


Four SNPs (T26A, A61C, T70A, and G130C) in the 5'-regulatory region of the caprine FSHR gene in different breeds of goats were detected by Guo et al. (2013). A polymorphism in the 200-bp indel of the promoter region in chicken FSHR was discovered by Kang et al. (2012), and 2 SNPs (C1506T and T1593C) in exon 10 in the bovine FSHR gene were reported by Rahal et al. (2000). However, only one report examined a polymorphism in exon 10 in the porcine FSHR gene. Wu and Wang (2012) detected 2 SNPs (C1166T and T1491C) in exon 10 of the FSHR gene in Xiaomeishan pigs, and the $\mathrm{C} \rightarrow \mathrm{T}$ mutation at the 1166-bp locus resulted in an amino acid change from threonine to isoleucine (Thr377Ile).

This is the first study to examine polymorphisms in exon 10 of the FSHR gene in Wannan Black, Berkshire, and BW pigs. The results showed that 3 SNPs (C1491T, G1885A, and C1977T) were detected, which did not result in amino acid changes at these positions, indicating that the nonsense mutation rate in the genome was much higher than the sense mutation rate (Jiang et al., 2002). In this study, only 1 SNP (C1491T) was detected in Wannan Black pigs, but 2 SNPs (G1885A and C1977T) were detected in Berkshire pigs, which were in close linkage disequilibrium. This could be because fewer samples of Wannan Black pigs were used in this study, and whether other mutations exist remains to be examined in much larger sample sizes. The chi-square test showed that the C1491T locus was in Hardy-Weinberg equilibrium in Wannan Black pigs, indicating that this locus was not affected by selection, mutation, or genetic drift (Pang et al., 2006). In contrast, the C1491T locus was in Hardy-Weinberg disequilibrium in BW pigs, indicating that there may be directional selection and mating in the breeding process of these pigs.

\section{Effect of FSHR polymorphisms on animal reproductive traits}

Many studies have indicated that the FSHR gene plays important roles in human hormone secretion, menstrual cycle, ovarian development, and other reproductive processes (Sairam and Subbarayan, 1997; Marson et al., 2008; Achrekar et al., 2009a; Balkan et al., 2010; Rendina et al., 2010; Dolfin et al., 2011; Kang et al., 2012; Grigorova et al., 2008, 2013). However, the relationship between FSHR polymorphisms and reproductive traits in swine has not been thoroughly examined. Wu and Wang (2012) found that the C1166T locus in exon 10 of FSHR can be used as a molecular marker for TNB and NBA in Chinese Xiaomeishan pigs, and sows with the AA genotype produced 1.95-fold more TNB and 1.66-fold more NBA than sows with the BB genotype at this locus (Wu and Wang, 2012). Rahal et al. (2000) detected 2 SNPs (C1506T and T1593C) in exon 10 of the bovine FSHR gene, and Lei et al. (2004) found that the C1506T locus could be used as a molecular marker for the twinning trait in Qinchuan cattle (see also Lei et al., 2004). Tan et al. (2008) identified a $\mathrm{C} \rightarrow \mathrm{T}$ mutation in exon 10 of the FSHR gene in Haimen goats, and the T allele showed a significant positive correlation with litter size. In the current study, the AB genotype in Wannan Black sows produced more TNB and NBA than AA genotype sows at the C1491T locus after the second parity and across all parities, respectively $(\mathrm{P}<0.01)$. DE haplotype Berkshire sows produced more TNB and NBA than either the DD or EE haplotype sows at the G1885A and $\mathrm{C} 1977 \mathrm{~T}$ locus in the first parity and in all parities $(\mathrm{P}<0.01)$. Therefore, our results suggest that the $\mathrm{T}$ allele of C1491T can be used as a molecular marker for litter size in Wannan black pigs, and the DE haplotype combination (linked loci GCTA) can be used as a molecular marker for litter size in Berkshire pigs. 


\section{ACKNOWLEDGMENTS}

Research supported by grants from the National Natural Science Foundation of China (\#31171200, \#31402037, and \#30771581), the Anhui Provincial Natural Science Foundation (\#1408085QC55 and \#1208085MC44), the Project of Anhui Province Scientific Technology Plan (\#1301031032), the Young Scientists Foundation of Anhui Agricultural University (\#2013ZR6), and the Transformation of Agriculture Scientific and Technological Achievements Foundation of China (\#2012GB2C300207).

\section{REFERENCES}

Achrekar SK, Modi DN, Desai SK, Mangoli VS, et al. (2009a). Follicle-stimulating hormone receptor polymorphism (Thr307Ala) is associated with variable ovarian response and ovarian hyperstimulation syndrome in Indian women. Fertil. Steril. 91: 432-439.

Achrekar SK, Modi DN, Desai SK, Mangoli VS, et al. (2009b). Poor ovarian response to gonadotrophin stimulation is associated with FSH receptor polymorphism. Reprod. Biomed. Online 18: 509-515.

Achrekar SK, Modi DN, Meherji PK, Patel ZM, et al. (2010). Follicle stimulating hormone receptor gene variants in women with primary and secondary amenorrhea. J. Assist. Reprod. Genet. 27: 317-326.

Balkan M, Gedik A, Akkoc H, Izci Ay O, et al. (2010). FSHR single nucleotide polymorphism frequencies in proven fathers and infertile men in Southeast Turkey. J. Biomed. Biotechnol. 2010: 640318.

Chu MX, Guo XH, Feng CJ, Li Y, et al. (2012). Polymorphism of 5' regulatory region of ovine FSHR gene and its association with litter size in Small Tail Han sheep. Mol. Biol. Rep. 39: 3721-3725.

Daelemans C, Smits G, de Maertelaer V, Costagliola S, et al. (2004). Prediction of severity of symptoms in iatrogenic ovarian hyperstimulation syndrome by follicle-stimulating hormone receptor Ser680Asn polymorphism. J. Clin. Endocrinol. Metab. 89: 6310-6315.

Dolfin E, Guani B, Lussiana C, Mari C, et al. (2011). FSH-receptor Ala307Thr polymorphism is associated to polycystic ovary syndrome and to a higher responsiveness to exogenous FSH in Italian women. J. Assist. Reprod. Genet. 28: 925-930.

Grigorova M, Punab M, Ausmees K and Laan M (2008). FSHB promoter polymorphism within evolutionary conserved element is associated with serum FSH level in men. Hum. Reprod. 23: 2160-2166.

Grigorova M, Punab M, Poolamets O, Sober S, et al. (2013). Study in 1790 Baltic men: FSHR Asn680Ser polymorphism affects total testes volume. Andrology 1: 293-300.

Guo XH, Li Y, Chu MX, Feng CJ, et al. (2013). Polymorphism of 5' regulatory region of caprine FSHR gene and its association with litter size in Jining Grey goat. Turk. J. Vet. Anim. Sci. 37: 497-503.

Jiang Z, Rottmann OJ, Krebs O, Chen J, et al. (2002). A missense mutation in the follicle stimulating hormone receptor (FSHR) gene shows different allele effects on litter size in Chinese Erhualian and German Landrace pigs. J. Anim. Breed. Genet. 119: 335-341.

Jun JK, Yoon JS, Ku SY, Choi YM, et al. (2006). Follicle-stimulating hormone receptor gene polymorphism and ovarian responses to controlled ovarian hyperstimulation for IVF-ET. J. Hum. Genet. 51: 665-670.

Kang L, Zhang NB, Zhang YJ, Yan HX, et al. (2012). Molecular characterization and identification of a novel polymorphism of $200 \mathrm{bp}$ indel associated with age at first egg of the promoter region in chicken follicle-stimulating hormone receptor (FSHR) gene. Mol. Biol. Rep. 39: 2967-2973.

Lei XQ, Chen H, Yuan ZF, Xu TS, et al. (2004). Single nucleotide polymorphism in cow follicle-stimulating hormone receptor gene and its association with bovine twinning traits. Chin. J. Biochem. Mol. Biol. 20: 34-37.

Livshyts G, Podlesnaja S, Kravchenko S, Sudoma I, et al. (2009). A distribution of two SNPs in exon 10 of the FSHR gene among the women with a diminished ovarian reserve in Ukraine. J. Assist. Reprod. Genet. 26: 29-34.

Marson EP, Ferraz JBS, Meirelles FV, Balieiro JCC, et al. (2008). Effects of polymorphisms of LHR and FSHR genes on sexual precocity in a Bos taurus x Bos indicus beef composite population. Genet. Mol. Res. 7: 243-251.

Marsters P, Kendall NR and Campbell BK (2003). Temporal relationships between FSH receptor, type 1 insulin-like growth factor receptor, and aromatase expression during FSH-induced differentiation of bovine granulosa cells maintained in serum-free culture. Mol. Cell. Endocrinol. 203: 117-127.

Mohiyiddeen L, Newman WG, McBurney H, Mulugeta B, et al. (2012). Follicle-stimulating hormone receptor gene polymorphisms are not associated with ovarian reserve markers. Fertil. Steril. 97: 677-681.

Pang WJ, Bai L and Yang GS (2006). Relationship among H-FABP gene polymorphism, intramuscular fat content, and 
adipocyte lipid droplet content in main pig breeds with different genotypes in Western China. Yi Chuan Xue Bao 33: 515-524.

Rahal P, Latronico AC, Kohek MBF, de Lucia RFS, et al. (2000). Polymorphisms in the bovine follicle-stimulating hormone receptor gene. Anim. Genet. 31: 280-281.

Rannikki AS, Zhang FP and Huhtaniemi IT (1995). Ontogeny of follicle-stimulating hormone receptor gene expression in the rat testis and ovary. Mol. Cell Endocrinol. 107: 199-208.

Rendina D, Gianfrancesco F, De Filippo G, Merlotti D, et al. (2010). FSHR gene polymorphisms influence bone mineral density and bone turnover in postmenopausal women. Eur. J. Endocrinol. 163: 165-172.

Rodini GP, Genro VK, Matte U, Pereira FS, et al. (2011). There is no complete linkage between the polymorphisms N680S and T307A of the follicular stimulating hormone receptor gene in fertile women. J. Assist. Reprod. Genet. 28: 221-224.

Sairam MR and Subbarayan VS (1997). Characterization of the 5' flanking region and potential control elements of the ovine follitropin receptor gene. Mol. Reprod. Dev. 48: 480-487.

Shi YY and He L (2005). SHEsis, a powerful software platform for analyses of linkage disequilibrium, haplotype construction, and genetic association at polymorphism loci. Cell Res. 15: 97-98.

Sudo S, Kudo M, Wada S, Sato O, et al. (2002). Genetic and functional analyses of polymorphisms in the human FSH receptor gene. Mol. Hum. Reprod. 8: 893-899.

Tan GM, Li YJ and Zhang L (2008). Study on the polymorphism of follicle-stimulating hormone receptor gene (FSHR) in Haimen goat. China Herbivores 4: 12-14.

Vilodre LC, Kohek MB and Spritzer PM (2008). Screening of follicle-stimulating hormone receptor gene in women with premature ovarian failure in southern Brazil and associations with phenotype. J. Endocrinol. Invest. 31: 552-557.

Weaver B and Wuensch KL (2013). SPSS and SAS programs for comparing Pearson correlations and OLS regression coefficients. Behav. Res. Methods 45: 880-895.

Wu JS and Wang JY (2012). Polymorphism of exon10 of FSHR gene and its relationship with litter size in Xiaomeishan pigs. Sci. Agric. Sin. 45: 2728-2736.

Yang WC, Li SJ, Chen L and Yang LG (2014). FSHR genotype affects estrogen levels but not pregnancy rates in Luxi cattle subjected to embryo transfer. Genet. Mol. Res. 13: 1563-1569.

Zhang S, Li W, Zhu C, Wang X, et al. (2012). Sertoli cell-specific expression of metastasis-associated protein 2 (MTA2) is required for transcriptional regulation of the follicle-stimulating hormone receptor (FSHR) gene during spermatogenesis. J. Biol. Chem. 287: 40471-40483.

Zhang SJ, Xiong YZ, Den CY, Xiao SM, et al. (2004). FSHR gene mutation and its effect on litter size in pigs. Asian Australas. J. Anim. Sci. 17: 179-182. 